\title{
WhatsApp Doc?
}

\section{Georgina Gould, ${ }^{1}$ Ramin Nilforooshan ${ }^{2}$}

${ }^{1}$ St Peter's Hospital, Chertsey, Surrey, UK

${ }^{2}$ Brain Science Unit, Abraham Cowley Unit, Chertsey, Surrey, UK

\section{Correspondence to}

Dr Georgina Gould, St Peter's Hospital, Chertsey, Surrey KT16 OPZ, UK;

georgiegould@doctors.org.uk

Accepted 28 March 2016 Published Online First 12 April 2016
CrossMark

To cite: Gould G,

Nilforooshan R. BMJ Innov

2016;2:109-110.
The first smartphone was launched only 8 years ago and already in that time enormous advances have been made in mobile phone technology. It is now possible to transmit a myriad of data forms at the touch of a button, such as pictures, videos and Global Position System coordinates. It is estimated that, in the UK, approximately $72 \%$ of the population and $98.9 \%$ of doctors currently own a smartphone, with numbers continuing to rise. $^{1}$

In hospitals, communication between doctors is 'formally' conducted via pagers. First introduced in the 1950s, the system is out-dated and impractical by today's standards. Contacting another doctor involves locating a landline, dialling their four-digit bleep number along with that phone extension, and then anchoring yourself to the phone and waiting for it to ring. In the meantime, you will be unable to continue working and will discourage others from using the line for fear of blocking the return call. On the receiving end, the message arrives with an ear-piercing alert and the fourdigit extension. The communication is one-way and lacks useful informationnamely, who is trying to contact you, for what purpose and with what level of urgency. Needless to say, this system has flaws, the most important of which is time wastage. Research suggests that a doctor who is frequently paged can spend up to a fifth of his or her time going through this rigmarole. ${ }^{2}$

Unsurprisingly then, the rising capability of smartphones is rendering this archaic system redundant. Latest research suggests that an astonishing number of doctors are now using their mobiles to communicate clinical information about patients at work: $64.7 \%$ are using SMS messaging and $33.1 \%$ are using equivalent web-based applications such as WhatsApp. ${ }^{1}$

This is a problem. National Health Service England has formal guidance on information governance, and on the use of WhatsApp in particular, stating that 'whatever the other merits of WhatsApp, it should never be used for the sending of information in the professional healthcare environment'. ${ }^{3}$ The risk is, of course, around data security and therefore patient confidentiality. The public psyche is particularly tuned in to these issues, now more than ever, with incidents such as the recent TalkTalk data hacking scandal reducing trust in data security. This is clearly an issue that needs to be tackled with expediency.

With these concerns in mind one might be forgiven for wondering what the advantages actually are in using such a system. We carried out a study in which we asked 40 junior doctors about their use of WhatsApp. The study produced two key findings. First, WhatsApp is used more by surgeons than by medics: as a percentage of their total day-to-day communication, it was $30 \%$ and $11 \%$, respectively. We broke down what was being communicated and found that over a third of all WhatsApp messages consisted of advice or support. WhatsApp is performing an essential function, providing juniors whose teams are fragmented between theatres and wards with a hotline to senior opinion.

The second interesting result was around doctors' perception of WhatsApp. It was felt to be a good thing in general by $72.5 \%$, with $80 \%$ reporting that it improves the relationship between grades and breaks down the traditional hierarchies that can stunt effective communication within a team. The majority of doctors using WhatsApp form a 'group' (within the app), consisting of members of the clinical team, so when a message is sent it is visible to all. This group-chat dynamic not only improves team cohesion through informal conversation but it enables juniors to contact seniors more easily where they may not previously have felt able to phone them directly.

It is clear that doctors will continue to use methods of communication that are 
most useful and efficient in practice. Clinical teams require either a bespoke system that can evolve to keep pace with technology while solving the issue of information governance, or a clearer set of regularly updated guidelines on appropriate use of web applications such as WhatsApp and its future iterations.

Competing interests None declared.

Provenance and peer review Not commissioned; externally peer reviewed.

\section{REFERENCES}

1 Mobasheri M, King D, Johnston M, et al. The ownership and clinical use of smartphones by doctors and nurses in the UK: a multicentre survey study. BMJ Innov 2015;1:174-81.

2 Health Service Journal. Pagers off: the end for the bleep [Internet]. 2013 (cited 3 December 2015). http://www.hsj.co. uk/topics/technology-and-innovation/pagers-off-the-end-forthe-bleep/5054609.fullarticle

3 Information Governance Bulletin No. 21 [Internet]. 1st ed. 2015 (cited 3 December 2015). https://www.england.nhs.uk/ wp-content/uploads/2015/01/ig-bull-21.pdf 